\title{
Nanodiamond dispersions in metallic matrices with different carbon affinity
}

\author{
D. Nunes ${ }^{* * *}$, J.B. Correia** and P.A. Carvalho $* * * *$ \\ *Associação Euratom/IST, Instituto de Plasmas e Fusão Nuclear - Laboratório Associado, Instituto Superior \\ Técnico, Av. Rovisco Pais, 1049-001, Lisboa, Portugal \\ **LNEG, Estrada do Paço do Lumiar, 1649-038 Lisboa, Portugal \\ ***ICEMS, Instituto Superior Técnico, Universidade de Lisboa Av. Rovisco Pais, 1049-001 Lisboa, Portugal
}

Dispersing nanodiamond (nD) particles in metallic matrices can be achieved by ball milling resulting in metaldiamond composite powders [1-7]. The matrices have been selected considering the whole range of carbon affinity: copper that shows extremely reduced affinity towards carbon phases, potentially compromising the composite interfaces, and nickel and tungsten that are mild and strong carbide formers, respectively, displaying thus intermediate and strong carbon affinities. For the latter matrices, dispersing carbon phases represent a challenge due to carbide conversion.

The materials produced are designated as $\mathrm{Cu}-10 \mathrm{nD}, \mathrm{Ni}-10 \mathrm{nD}$ and $\mathrm{W}-20 \mathrm{nD}$ (where 10 and 20 indicate the atomic fraction of $\mathrm{nD}$ ). Close monitoring of the milling conditions enabled to homogeneously disperse the carbon phases and obtain nanostructured matrices (Figures 1 (a-c)), as well as to minimize milling media contamination and carbide formation, especially in the case of the W-based composite. Apparent interfacial bonding could be inferred the from transmission electron microscopy (TEM) images.

The metallic matrices have been subsequently dissolved to allow for a detailed analysis of nanodiamond. Electron diffraction demonstrated that its crystalline structure was preserved during milling (Figure 2). Microhardness measurements revealed remarkable strength enhancements of the nanostructured composites over that of pure metals of comparable grain sizes [9] (Table 1). The strengthening mechanisms that justify the hardness increments in $\mathrm{Cu}-10 \mathrm{nD}$ and $\mathrm{Ni}-10 \mathrm{nD}$ include second-phase reinforcement (due to the potential load bearing ability of diamond), as well as Orowan and solid solution strengthening. The hardening effect observed in the $\mathrm{W}-20 \mathrm{nD}$ composite over that of pure milled tungsten is probably related to the nanodiamond reinforcement, nevertheless the influence of a fine dispersion of carbides cannot be ruled out [3].

This work has been performed under the Contract of Association between EURATOM and Instituto Superior Tecnico. Financial support was also received from the Fundação para a Ciência Tecnologia (FCT) grants with references PTDC/CTM/100163/2008, Pest-OE/SADG/LA0010/2011 and PEST-OE/CTM-UI0084/2011.

\section{References}

1. Nunes D. et al., Mater. Sci. Eng. A, 528:8610, 2011.

2. Nunes D. et al., Acta Mater., 60:737-747, 2012.

3. Nunes D. et al., J. Nuclear Mater., 426:115-119, 2012.

4. Nunes D. et al., Phys. Scr., T145:014069, 2011.

8. Zhao M. et al., J. Alloys Compd., 361:160-164, 2003. 

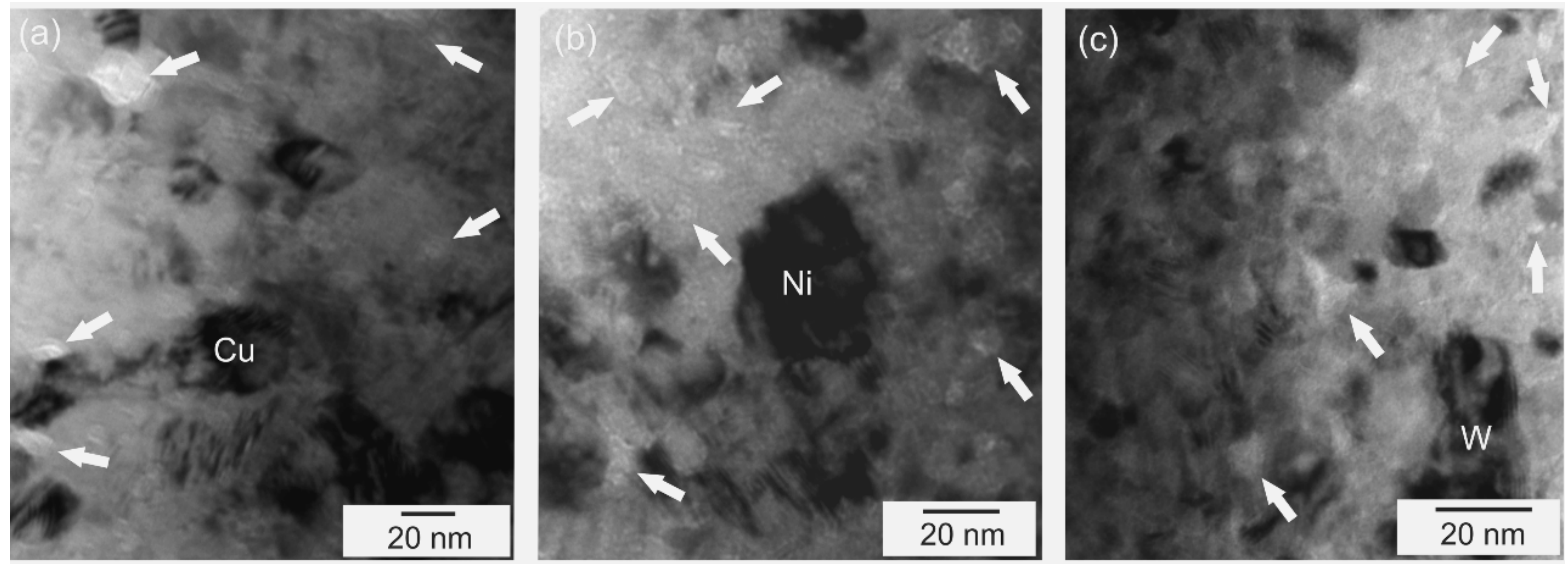

Figure 1. (a) Bright-field TEM images of the milled composites. (a) $\mathrm{Cu}-10 \mathrm{nD}$ milled for $4 \mathrm{~h}$ at $400 \mathrm{rpm}$, (b) Ni$10 \mathrm{nD}$ milled for $4 \mathrm{~h}$ at $200 \mathrm{rpm}$ and (c) W-20nD milled for $4 \mathrm{~h}$ at $200 \mathrm{rpm}$.

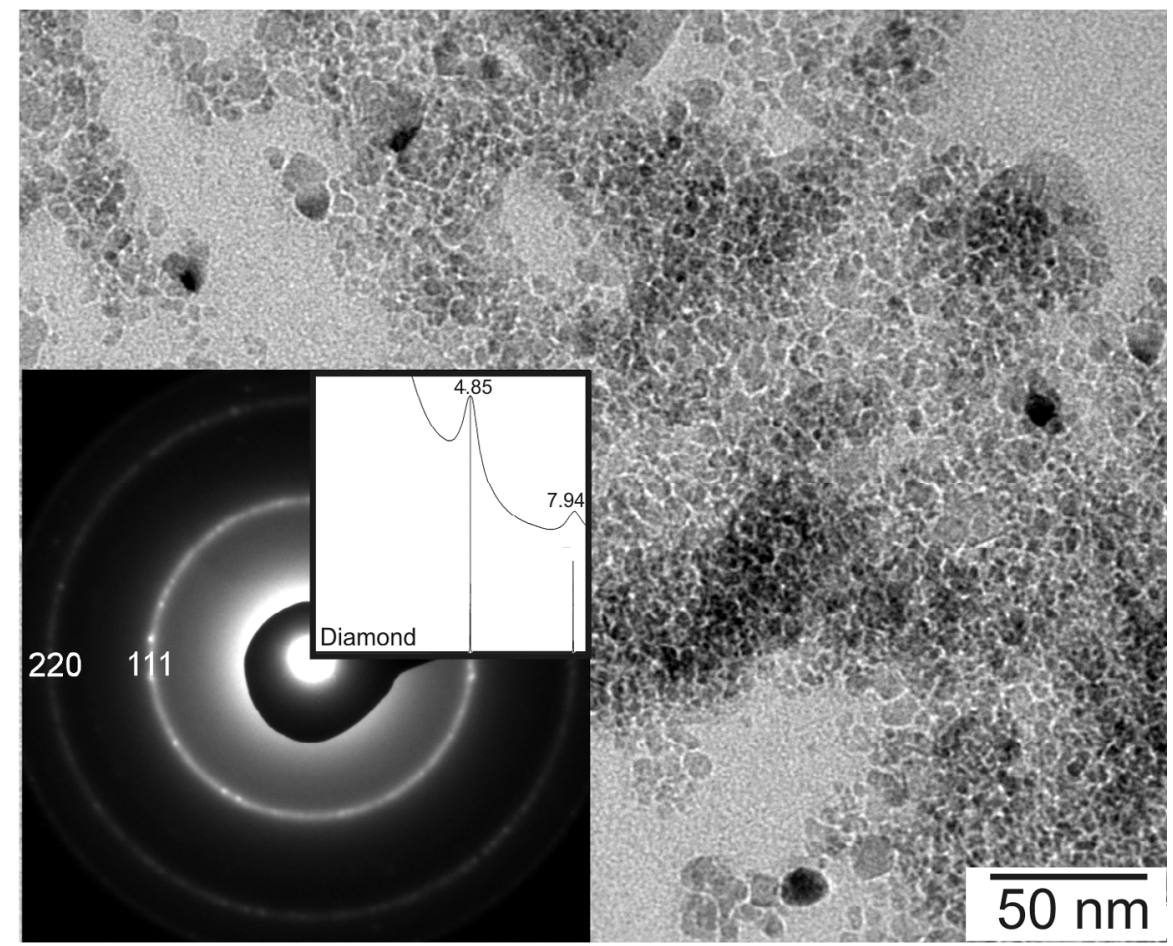

Figure 2. Typical bright-field TEM image of nanodiamond powder extracted from the milled composites. The characteristic ring diffraction pattern with an integrated radial profile demonstrates that the nanodiamond particles preserved the structure during milling (diamond simulation included with legend in $\mathrm{nm}$ ).

Table 1. Microhardness values of pure copper, nickel and tungsten, and milled $\mathrm{Cu}-10 \mathrm{nD}, \mathrm{Ni}-10 \mathrm{nD}$ and $\mathrm{W}-20 \mathrm{nD}$ composites.

\begin{tabular}{|c|c|}
\hline Conditions & Vickers Microhardness (GPa) \\
\hline Nanostructured pure copper (10-30 nm) [8] & 2.5 \\
\hline As-milled Cu-10nD (4 h) [1] & $3.62 \pm 0.04$ \\
\hline Nanostructured pure nickel (10-20 nm) [8] & 6.0 \\
\hline As-milled Ni-10nD (4 h) [2] & $8.83 \pm 0.14$ \\
\hline As-milled pure tungsten (4 h) [3] & $16.1 \pm 0.8$ \\
\hline As-milled W-20nD (4 h) [3] & $21.4 \pm 1.1$ \\
\hline
\end{tabular}

